\title{
Camphor (Cinnamomum camphora), a traditional remedy with the history of treating several diseases
}

\author{
Rafie Hamidpour, Soheila Hamidpour, Mohsen Hamidpour, \\ Mina Shahlari
}

\begin{abstract}
Introduction: The purpose of this literature review is to gain knowledge of the long history, wide variety and extensive applications of camphor, both in traditional and modern medicine. Camphor (Cinnamomum camphora) is obtained from the wood of camphor tree. It has been used for centuries, throughout the world as a remedy for treating variety of symptoms such as inflammation, infection, congestion, pain, irritation, etc. The studies have shown that some of the components of Cinnamomum camphora have suppressive and antimutagenic effect in number of human cancer cells without harming the healthy cells. In this paper our focus is on the use of camphor as a remedy for daily minor problems as well as reporting some information about the new applications of this traditional medicine to treat or prevent some serious life-threatening diseases sucha as cancer and diabetes. We hope to get the attention of researchers for conducting more studies on the effects of camphor on patients with memory and brain disorders as well.
\end{abstract}

Rafie Hamidpour ${ }^{1}$, Soheila Hamidpour ${ }^{2}$, Mohsen Hamidpour $^{3}$, Mina Shahlari ${ }^{4}$

Affiliations: ${ }^{1} \mathrm{PhD}$, President, Pars Bioscience, Leawood, Kansas, United States; 2MD, Pars Bioscience, Leawood, Kansas, United States; ${ }^{3} \mathrm{PhD}$, Pars Bioscience, Leawood, Kansas, United States; ${ }^{4}$ B.A. in Biology, Pars Bioscience, Leawood, Kansas, United States.

Corresponding Author: Rafie Hamidpour, Pars Bioscience LLC, 14109 Cambridge Lane, Leawood, Kansas, United States 66224; Ph: (913) 432-0107; Fax: (913) 432-5708; Email: rafie@parsbioscience.com

Received: 30 August 2012

Accepted: 26 October 2012

Published: 01 February 2013
Keywords: Camphor, Cinnamomum camphora, Application, Treatment, Cancer

$$
* * * * * * * *
$$

Hamidpour R, Hamidpour S, Hamidpour M, Shahlari M. Camphor (Cinnamomum camphora), a traditional remedy with the history of treating several diseases. International Journal of Case Reports and Images 2013;4(2):86-89.

$* * * * * * * * *$

doi:10.5348/ijcri-2013-02-267-RA-1

\section{INTRODUCTION}

Camphor (Cinnamomum camphora) is a white, crystalline substance with a strong odor and pungent taste, derived from the wood of camphor laurel (Cinnamomum camphora) and other related trees of laurel family. Camphor tree is native to China, India, Mongolia, Japan and Taiwan and a variety of this fragrant evergreen tree is grown in Southern United States; especially in Florida [1, 2]. Camphor is obtained through steam distillation, purification and sublimation of wood, twigs and bark of the tree [3]. There are many pharmaceutical applications for camphor such as topical analgesic, antiseptic, antispasmodic, antipruritc, antiinflammatory, anti-infective, rubefacient, contraceptive, mild expectorant, nasal decongestant, cough suppressant, etc. [3-5]. Camphor is easily absorbed through the skin and can also be administrated by injection, inhalation and ingestion $[3,6]$.

Camphor has several chemical varieties, each with different essential oil compositions [1]. The leaf of Cinnamomum camphora contains camphor, as the main component along with cineol, linalool, eugenol, limonene, safrole, $\alpha$-pinene, $\beta$-pinene, $\beta$-myrecene, $\alpha$ humulene, p-cymene, nerolidol, borneol, camphene and some other components $[1,5,7,8]$. 


\section{APPLICATIONS}

Camphor is a natural product with many applications in traditional and modern medicines. Traditionally, camphor has been used as a cold remedy for the relief of chest congestion and the treatment of inflammation related diseases such as rheumatism, sprains, bronchitis, asthma and muscle pain [9]. Camphor is usually prepared as a balm, oil or cream to relieve the pain and inflammation in joints and muscles. Camphor oil (20\% camphor in cotton seed oil), when applied on the skin produces the feeling of coolness which is related to the stimulation of nerve endings sensitive to cold. Camphor activates some of TRP (transient receptor potential) channels like TRPV1, TRPV3, TRPM8 and inhibits TRPA1, causing warm sensation, excitation and desensitization of sensory nerves, relieving the pain, itch and irritation in applied area $[4,10-12]$.

There are many reports which prove that the use of camphor, solely or in combination with other treatments can be very effective for treating and preventing some serious diseases. A cancer study says that the use of camphor odor as a conditioning agent for the cancer cells of YC8 lymphoma in mice could have a suppressive effect on the growth of YC8 tumor, when it is combined with immunotherapy treatment [13]. Camphor also can be potential radiosensitizing agent in radiotherapy. Treatment with camphor prior to a radiation showed reduced growth of tumor volume [3].

A camphor based drug called 714-X, was developed by a Canadian researcher more than forty years ago and it is reported by some institutions, to be effective on the treatment of some patients with cancer, especially breast and prostate cancer [14]. Padma 28 is another multi compound herbal preparation, based on camphor formula which has shown to be effective against chronic inflammatory diseases. The result of a study indicates that Padma 28 has the ability to suppress the development of autoimmune diabetes in female nonobese diabetic (NOD) mice which could be an experimental model for type 1 diabetes mellitus in humans [15].

There are a number of applications for different parts of Cinnamomum camphora tree. The study of Cinnamomum camphora leaves extract (CLE) has shown the protective effects against DNA damage and biochemical changes in mice caused by atrazine (AT) which is one of the commonly used grass and weed herbicides [9]. The widespread usage of AT has caused contamination in the environment, resulting in genotoxicity and biochemical disturbances in animals and human cells. In this experiment, all the tested tissues which were treated with CLE showed a significant and time dependant decrease in chromosomal abnormalities and DNA damage [9]. Two ribosome inactivating proteins (RIPs), cinnamomin and camphorin are found in the seeds of Cinnamomum camphora; studies have shown their inhibitory effect on the cultured carcinoma cells [16]. In addition, cinnamomin has shown to have inhibitory effect on the growth of solid melanoma in the skin of the nude mouse [16]. The application of RIPs can be very significant in drug development and crop-plant technology due to their toxicity against viruses, tumor cells, insects and plant fungal pathogens [17].

One use of camphor is for carbon nanotubes (CNT). In recent years, the finding of CNT which are made of very light and strong fibers of one atom-thick sheet of carbons, rolled in tubes, have been very exciting developments with many applications in medicinal and industrial fields [18]. One of the most important uses of CNT is in the cancer treatments. Single wall CNT can be used as a drug delivery vehicle with high surface area to deliver chemotherapy drugs to the tumor cells and later, these purely carbon-made nanotubes can be excreted out of the body by biliary pathway without causing any toxicity [19]. Carbon nanotubes to this point are synthesized from purified petroleum products like methane, benzene, acetylene, etc. However, camphor can be the environment-friendly, alternative new option [18]. Camphor is a botanical hydrocarbon which is very cheap and can be easily cultivated without fear of shortages unlike petroleum products. Therefore, camphor is an excellent carbon source for the production of a high yield, high purity and high efficiency carbon nanotubes in future [20].

The essential oil of Cinnamomum camphora and some other aromatic camphor containing plants such as sage, rosemary and basil which are widely used in traditional medicines contain monoterpenes. The studies have shown that some essential oil components, especially monoterpenes have suppressive and antimutagenic effect in number of human cancer cells including colon cancer, gastric cancer, liver tumor, breast cancer, leukemia and others [21]. Most cancer chemotherapy treatments include highly cytotoxic drugs against proliferating cancer cells as well as healthy cells which can be harmful for the body. With a different mechanism of action, essential oils with their monoterpene components can have multiple pharmacological tumor-suppressive activities, mostly without such harm [21].

Many studies have been done about the various applications and benefits of camphor in pharmaceutical, industrial and environmental fields. Camphor has been used traditionally for many years as a remedy for the relief of pain, inflammation and irritation in the body and skin. Recent studies have focused on the role of camphor in preventing and curing serious and life- threatening diseases, when it is used purely or combined with other treatments. The study on some species in the Lauraceae family, shows that a number of extracts have significant antioxidant, anti-inflammation and anti-tumor activities [7, 21, 22]. These studies indicate that Lauraceae tree species and other camphor containing plants could have very important potential nutraceutical and pharmaceutical applications in the future [22], taking medicine just another step forward. 


\section{DOSAGE AND TOXICITY}

Camphor like any other medication should be used for certain patients within the indicated dosages and contraindications [3]. The concentration of $3-11 \%$ has been approved by the FDA for topical use as a pain reliever and anesthetic [23]. Camphor and other terpenoid compounds do not accumulate in the environment since many soil bacteria like Pseudomonas putida readily degrade these compounds [24]. Although herbal medicines and essential oils have been widely used in folk and modern alternative medicine for many years and have shown to be very effective in curing many symptoms and diseases, the misuse of them can be very harmful for the body causing serious problems [25]. Camphor intoxication has been reported in humans and especially children but mostly because of accidental ingestion or exceeding the recommended amount [3].

\section{CONCLUSION}

Camphor has been used traditionally for many years, solely or in combination with other treatments for the relief of pain, inflammation and irritation in body and skin. It can also be very effective in treating and preventing some serious, life threatening diseases. Considering the growing number of cancer patients, Cinnamomum camphora and its components should be investigated further as a viable option in the treatment of different types of cancer. In addition, more studies on the application of camphor for patients with memory disorders and brain dysfunctions such as in Alzheimer's and autism are needed.

$* * * * * * * * *$

\section{Author Contributions}

Rafie Hamidpour - Conception and design, Analysis and interpretation of data, Critical revision of the article, Final approval of the version to be published

Soheila Hamidpour - Analysis and interpretation of data, Critical revision of the article, Final approval of the version to be published

Mohsen Hamidpour - Analysis and interpretation of data, Critical revision of the article, Final approval of the version to be published

Mina Shahlari - Acquisition of data, Drafting the article, Final approval of the version to be published

\section{Guarantor}

The corresponding author is the guarantor of submission.

\section{Conflict of Interest}

Authors declare no conflict of interest.

\section{Copyright}

(C) Rafie Hamidpour et al. 2013; This article is distributed under the terms of Creative Commons
Attribution 3.0 License which permits unrestricted use, distribution and reproduction in any means provided the original authors and original publisher are properly credited. (Please see www.ijcasereportsandimages.com /copyright-policy.php for more information.)

\section{REFERENCES}

1. Caren D Frizzo, Ana C Santos, Natalia Paroul, et al. Essential Oils of Camphor Tree (Cinnamomum Camphora Nees \& Eberm) Cultivated in Southern Brazil. Brazilian Archives of Biology and Technology 2000;43(3).

2. Starr Forest, Starr Kim, Loop Lloyd. Cinnamomum Camphora. Rep. Maui, Hawai'i: United States Geological Survey-Biological Resources Division 2003.

3. Zuccarini Paolo. Camphor: Risks and Benefits of a Widely Used Natural Product. J Appl Sci Environ Manage 2009;13(2):69-74.

4. Sherkheli MA, Benecke H, Doerner JF, et al. Monoterpenoids induce agonist-specific desensitization of transient receptor potential vanilloid-3 (TRPV3) ion channels. J Pharm Pharm Sci 2009;12(1):116-28.

5. Chelliah Abiya D. Biological Activity Prediction of an Ethno Medicinal Plant Cinnamomum Camphora Through Bio-informaticts. Ethnobotanical Leaflets 2008;12:181-90.

6. Segal Sydney, Cohen Sanford N, Freeman John, et al. American Academy of Pediatrics. Committee on Drugs. Camphor: Who needs it? Pediatrics 1978;62(3):404-6.

7. Chen-Lung Ho, Eugene I-Chen Wang, Yu-Chang Su. Essential Oil Compositions and Bioactivities of the Various Parts of Cinnamomum Camphora Sieb.Var. Linaloolifera Fujuta 2009;31(2):77-96.

8. Joshi SC, Padalia RC, Bisht DS, Mathela CS. Terpenoid Diversity in the Leaf Essential Oils of Himalayan Lauraceae Species. Chemistry \& Biodiversity 2009;6(9):1364-73.

9. Asmaa S Salman, Ayman A Farghaly, Souria M Donya, Fawzia Shata. Protective Effect of Cinnamomum Camphora Leaves Extract Against Atrazine Induced Genotoxicity and Biochemical Effect on Mice. Journal of American Science 2012;8(1):190-6.

10. Jara-Oseguera A, Simon SA, Rosenbaum T. TRPV1: On the Road to Pain Relief. Curr Mol Pharmacol 2008;1(3):255-69.

11. Xu H, Blair NT, Clapham DE. Camphor Activates and Strongly Desensitizes the Transient Receptor Potential Vanilloid Subtype 1 Channel in a VanilloidIndependent Mechanism. J Neurosci 2005;25(39):8924-937.

12. Vogt-Eisele AK, Weber K, Sherkheli MA, et al. Monoterpenoid Agonists of TRPV3. British Journal of Pharmacology 2007;151(4):530-40.

13. Ghanta VK, Hiramoto NS, Solvason HB, Soong SJ, Hiramoto RN. Conditioning: a new approach to immunotherapy. Cancer Res 1990;50(14):4295-9.

14. Kaegi E. Unconventional therapies for cancer: 6. 714$X$. Task Force on Alternative Therapeutic of the Canadian Breast Cancer Research Initiative. Canadian Medical Association Journal 1998;158(12):1621-4. 
15. Lola Weiss, Vivian Barak, Itamar Raz, Reuven Or, Shimon Slavin, Isaac Ginsburg. Herbal Flavonoids Inhibit the Development of Autoimmune Diabetes in NOD Mice: Proposed Mechanisms of Action in the Example of PADMA 28. Alternative Medicine Studies 2011;1(e1):1-6.

16. Ling J, Liu WY. Cytotoxicity of Two New RibosomeInactivating Proteins, Cinnamomin and Camphorin, to Carcinoma Cells. Cell Biochem Funct 1996;14(3):157-61.

17. Liu RS, Wei GQ, Yang Q, He WJ, Liu WY. Cinnamomin, A Type II Ribosome-Inactivating Protein, Is A Storage Protein in the Seed of the Camphor Tree (Cinnamomum Camphora). Biochemical Society Journal 2002;362(Pt 3):659-3.

18. Mukul Kumar, Yoshinori Ando. Single-wall and Multi-wall Carbon Nanotubes from Camphor-A Botanical Hydrocarbon. Diamond and Related Materials 2003;12:1845-50.

19. Liu Z, Chen K, Davis C, et al. Drug Delivery with Carbon Nanotubes for In vivo Cancer Treatment. Cancer Res 2008;68(16):6652-60.

20. Mukul Kumar, Yoshinori Ando. Carbon Nanotubes from Camphor: An Environment- Friendly
Nanotechnology. Journal of Physics: Conferences Series 2007;61:643-46.

21. Edris AE. Pharmaceutical and Therapeutic Potentials of Essential Oils and Their Individual Volatile Constituents: A Review. Phytother Res 2007;21(4):308-23.

22. Lin TC, Chu FH, Tseng YH, Tsai JB, Chang ST, Wang SY. Bioactivity Investigation of Lauraceae Trees Grown in Taiwan. Pharmaceutical Biology 2007;45(8):638-44.

23. MAJED M HANIA. Topical Medicine for Treatment of the Musculoskeletal. International Journal of ChemTech Research 2010;2(1):700-5.

24. Ngadiman N, Hikaru Suenaga, Masatoshi Goto, Kensuke Furukawa. Distribution of Camphor Monooxygenase in Soil Bacteria. Indonesian Journal of Biotechnology 2005;10(2):848-53.

25. Grbic G, Culic M, Martac L, Sokovic M, Spasic S, Dokovic D. Effect of Camphor Essential Oil on Rat Cerebral Cortex Activity as Manifested by Fractal Dimension Changes. Arch Biol Sci Belgrade 2008;60(4):547-3.
Access full text article on other devices

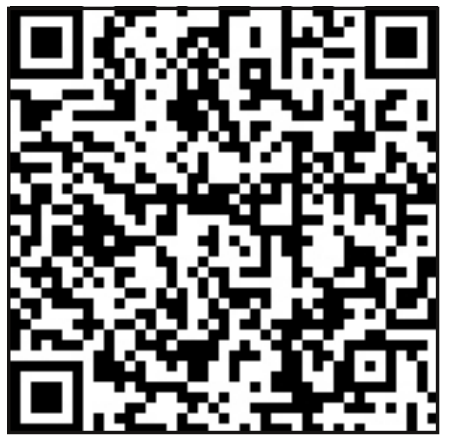

Access PDF of article on other devices

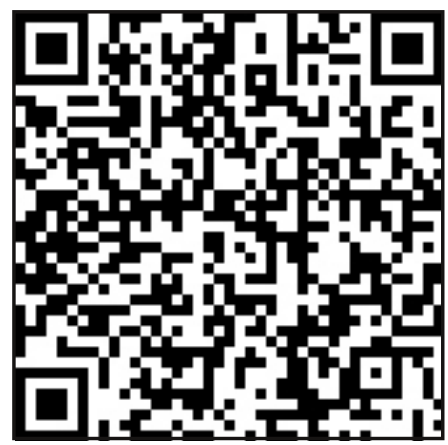

